\title{
A New Medium for the Isolation and Growth of Auxotrophic Mutants of the Blue-green Alga Anacystis nidulans
}

\author{
By M. HERDMAN, S. F. DELANEY AND N. G. CARR \\ Department of Biochemistry, University of Liverpool, Liverpool L69 $3 B X$
}

(Received I 2 March 1973; revised 27 June 1973)

\begin{abstract}
SUMMARY
A complete medium of defined composition has been developed for quantitative growth of wild-type and auxotrophic mutant strains of Anacystis nidulans. This medium has proved to be more satisfactory than other complex media (for example casein hydrolysate, yeast extract) for both the isolation and the growth of auxotrophs. Rigorous control of the $\mathrm{pH}$ of complete and other supplemented media is essential for quantitative growth on agar. Four diagnostic media are described which each contain a different combination of the supplements used in the complete medium and facilitate the identification of the nutritional requirements of mutants. By using these media a number of auxotrophs have been isolated including five with novel phenotypes which require respectively (i) thiamine, (ii) $p$-aminobenzoic acid, (iii) a combination of pyruvate or acetate plus malate or succinate or fumarate, (iv) serine or glycine and (v) adenine.
\end{abstract}

\section{INTRODUCTION}

Although morphological and drug-resistant mutants of several species of blue-green algae have been isolated with relative ease, the isolation of auxotrophic mutants has proved more difficult (see review by Van Baalen, 1973) and several authors have commented on their failure to isolate mutants of this type (Asato \& Folsome, 1969; Houghton, I971 ; Kaney \& Dolack, 1972). Mutants defective in the enzymes of nitrate assimilation have been recognized for some time in Anacystis nidulans (Van Baalen, 1965) and in Agmenellum quadruplicatum (Stevens \& Van Baalen, 1970) and such mutants are the most common auxotrophic type produced by treatment with $N$-methyl- $N^{\prime}$-nitro- $N$-nitrosoguanidine (Herdman \& Carr, 1972). They are easily isolated, even on non-supplemented medium on which they grow as yellow colonies presumably because they lack phycocyanin, known to be a protein storage material (Allen \& Smith, I969). Auxotrophs of other phenotypes have been found only at very low frequency. Strains of Anacystis nidulans requiring phenylalanine, methionine, biotin, acetate or a reduced sulphur source, together with the more frequent mutants blocked in nitrate reduction, were described by Herdman \& Carr (1972). Ingram, Pierson, Kane, Van Baalen \& Jensen (1972) described a tryptophan-requiring mutant of Agmenellum quadruplicatum which has a defective tryptophan synthetase A protein.

A major difficulty encountered in studies of the mutagenesis of blue-green algae has been the development of suitably supplemented media containing amino acids, bases, vitamins and organic acids. Selective media have generally contained one or only a few supplements, and therefore screening for all potential growth requirements has been tedious. Media more fully supplemented with, for example, casein hydrolysate permitted the isolation of mutants of Phormidium mucicola (Srivastava, 1969) and Agmenellum quadruplicatum (Stevens \& Van Baalen, 1970), whose precise nutritional requirements were not established. 
The physical conditions for the mutagenesis and selection of a restricted range of mutant strains have been described (Herdman \& Carr, 1972). This communication describes the growth of Anacystis nidulans on complex media, the development of a chemically defined complete medium which supports the growth of all auxotrophs tested, and the use of this medium in the isolation and rapid identification of mutant strains.

\section{METHODS}

Organism. The wild-type organism (oroo) was Anacystis nidulans, no. 625 of the Culture Collection of Algae, Department of Botany, Indiana University, Bloomington, Indiana, U.S.A. Auxotrophic strains 2 I I I (nit A; deficient in nitrate-reductase activity), II I4 (nitB; deficient in nitrite-reductase activity), II2I (cys), II4I (bio), II 7I (met) and 2II2 (nit met) were isolated by the methods previously described (Herdman \& Carr, 1972). Strain I2II (carrying $t h i-I$ ) requires thiamine and was isolated after exposure to ethyl methanesulphonate.

Media. The minimal medium employed was that described by Allen (1968) with the following modifications $(\mathrm{g} / \mathrm{l}): \mathrm{CaCl}_{2} .2 \mathrm{H}_{2} \mathrm{O}, 0.038 ; \mathrm{Na}_{2} \mathrm{SiO}_{3} .5 \mathrm{H}_{2} \mathrm{O}, 0.058$; citric acid, $0.012 ; \mathrm{FeSO}_{4} .7 \mathrm{H}_{2} \mathrm{O}, 0.006$; ferrous citrate omitted. Salts were dissolved in water which had been de-ionized and distilled in an all-glass apparatus. For surface growth on agar, plates were prepared as described by Allen (1968) but at least 2 to 4 days before required and if necessary dried at 30 to $34{ }^{\circ} \mathrm{C}$ overnight before use. Medium for use in liquid cultures was supplemented with sodium bicarbonate, I g/l. Supplements were added as appropriate to the minimal medium and the $\mathrm{pH}$ adjusted to 9.6 before autoclaving.

Growth conditions. Stock cultures of Anacystis nidulans were maintained on $1 \cdot 5 \%(w / v)$ agar slopes. For the growth and maintenance of mutant strains supplements were added as described (Herdman \& Carr, 1972) with the exception of ammonium chloride $(0.36 \mathrm{~g} / \mathrm{l})$ and thiamine $(2 \mathrm{mg} / \mathrm{l})$. Slopes were normally inoculated within $24 \mathrm{~h}$ of preparation and incubated under the same conditions as Petri dishes (see below). After incubation for one to two days the tubes were sealed with Parafilm and stored on a well-illuminated laboratory shelf at room temperature.

Liquid cultures were grown in $250 \mathrm{ml}$ conical flasks, containing $100 \mathrm{ml}$ of medium, at $34^{\circ} \mathrm{C}$ in a Gallenkamp illuminated orbital shaker. Illumination was provided by $3 \times 30 \mathrm{~W}$ Atlas 'Gro-Lux' fluorescent lamps at a distance of 12 in, and a constant flow $(3 \mathrm{l} / \mathrm{h})$ of carbon dioxide was passed into the shaker. This caused a replacement of approx. $2 \%$ of the total volume of the incubator gas space/h. For the determination of growth rate, cultures were grown in $250 \mathrm{ml}$ side-arm conical flasks and turbidity was measured in an EEL colorimeter. Cultures of smaller volume (Io or $20 \mathrm{ml}$ ) were grown in boiling tubes at $34{ }^{\circ} \mathrm{C}$, 5 to 7 in from a bank of $3 \times 40 \mathrm{~W}$ warm white fluorescent lamps and gassed with air: $\mathrm{CO}_{2}$ $(95: 5, v / v)$ through a glass tube.

For quantitative surface growth on agar, plates were inoculated as described by Herdman, Faulkner \& Carr (1970) and incubated at $34 \pm \mathrm{I}{ }^{\circ} \mathrm{C}$ on open wire-mesh shelves, 2.5 in from banks of $40 \mathrm{~W}$ warm white fluorescent lamps placed 6 in apart. The relative humidity of the room was maintained at $75 \pm 5 \%$ by a Defensor model $300 \mathrm{I}$ humidifier, and air was circulated by an electric fan. Microcolonies were visible at $\times 10$ magnification after $36 \mathrm{~h}$; colonies were normally scored after 3-4 days' incubation.

It was observed that both the quality and the quantity of emission changed with the age of the fluorescent lamps. All lamps were routinely replaced after 6 months. 


\section{RESULTS AND DISCUSSION}

Growth on complex media. In previous attempts to isolate auxotrophic mutants of bluegreen algae, media have been supplemented with casein hydrolysate at concentrations of $0.01 \%$ (Stevens \& Van Baalen, 1970), 0.025\% (Srivastava, 1969) and 0.1 \% (Kaney \& Dolack, 1972), and yeast extract has been added at 0.01 \% (Kaney \& Dolack, 1972). These supplements were insufficient to support the growth of a selection of auxotrophs (2III III4, II2I, II4I, II7I, I2I I and 2I I2) when they were streaked on to agar supplemented at these low concentrations. The same mutants grew well, however, when streaked on to agar suitably supplemented with increased levels $(0.5 \%)$ of casein hydrolysate or yeast extract, and also on bacteriological peptone $(0.5 \%)$ or nutrient broth $(2.5 \%)$, except that the bio strain II $4 \mathrm{I}$ failed to grow on casein hydrolysate and the met strains II $7 \mathrm{I}$ and $2 \mathrm{II} 2$ grew on neither yeast extract nor nutrient broth. Unfortunately, these complex but nonchemically defined media did not support the growth of single colonies even when the wildtype strain was plated for colony growth. Complex media of the types described are therefore unsuitable for the isolation of mutants since, when present at the concentrations necessary to support the growth of mutants, the supplements inhibit the growth of single colonies. It may be possible to develop a complex medium containing these supplements which will support the growth of both streaks and single colonies. However, the synthetic complete medium described below fulfils both of these requirements and, since it has a defined composition, has the additional advantage of facilitating the identification of the nutritional requirements of mutants.

Composition of the complete medium. The new synthetic complete medium contained amino acids, nucleic-acid bases, organic acids and vitamins; the composition is described in the legend to Table I. In most cases the levels of supplements were lower than those previously described (Herdman \& Carr, 1972). Since certain vitamins are photolabile (e.g. riboflavin, $\mathrm{B}_{12}$ ), the medium was supplemented only with those considered to be stable under the growth conditions.

Growth on complete medium. The growth rates and final yields of wild type and mutants in the liquid complete medium were similar to wild type in liquid minimal medium (O.I4 doublings $/ \mathrm{h}, 5 \cdot \mathrm{I} \mathrm{mg} / \mathrm{ml}$ ). All the strains grew well, both as streaks and as single colonies, on solid complete medium although the viability and growth rate of colonies varied markedly with the $\mathrm{pH}$ of the medium. The final $\mathrm{pH}$ on the surface of the agar differed from the initial $\mathrm{pH}$ of the double-strength supplemented salts solution. Optimum growth on complete medium was achieved when the $\mathrm{pH}$ was adjusted to $8 \cdot 0$ before autoclaving, giving a final $\mathrm{pH}$ of 7.0 as measured by $\mathrm{BDH}$ Universal Indicator. Relatively small changes from the optimum resulted in a marked reduction in viability (Table 2). Optimum surface growth on minimal medium, media containing single supplements, and diagnostic media containing different combinations of supplements (described below) also occurred at a final $\mathrm{pH}$ of $7 \cdot 0$, and to achieve this $\mathrm{pH}$ it was necessary to adjust diagnostic media I, II and III to $8 \cdot 0$ and minimal medium, diagnostic medium IV and other supplemented media to 9.6 before autoclaving. This variation in the initial $\mathrm{pH}$ of media reflects their different buffering capacities; rigorous control of the final $\mathrm{pH}$ of media was essential for growth of Anacystis nidulans on surface agar. The adverse effects of incorrect $\mathrm{pH}$ on the growth on complex media have apparently not been previously considered.

Identification of mutants. Mutants were identified by a method similar to that described by Holliday (1956) and Takahashi (1959). Four diagnostic media were developed, each containing a different combination of the supplements as shown in Table $\mathrm{r}$. A mutant with 


\title{
Table $\mathrm{I}$. The composition of complete and diagnostic media and the growth responses of mutants on diagnostic media
}

\begin{abstract}
The components of the complete medium were divided into nine supplement groups and each group was stored as a stock solution of $100 \times$ final concentration at $4{ }^{\circ} \mathrm{C}$ for not more than one month. Methionine and cysteine were unstable in solution and were weighed out as required. The supplement groups contained: (I) glutamic acid, proline, arginine; (2) aspartic acid, lysine $\mathrm{HCl}$, threonine, methionine; (3) tyrosine, tryptophan, phenylalanine, histidine $\mathrm{HCl}, \mathrm{pH}$ adjusted to I I 0 ; (4) serine, glycine, cysteine; (5) alanine, valine, leucine, isoleucine; (6) adenine, thymine, cytosine, uracil, $\mathrm{pH}$ adjusted to $\mathrm{I} \cdot 5$; (7) thiamine, $p$-aminobenzoic acid, nicotinic acid, biotin; (8) succinic acid, citric acid, sodium pyruvate, sodium acetate $3 \mathrm{H}_{2} \mathrm{O}$, sodium fumarate, sodium hydrogen malate; (9) ammonium chloride.

The final concentration of amino acids and bases was $10^{-4} \mathrm{M}$, except those of group $3\left(5 \times 10^{-5} \mathrm{M}\right)$ and cysteine $\left(5 \times \mathrm{IO}^{-4} \mathrm{M}\right)$. Organic acids were used at $5 \times 10^{-4} \mathrm{M}$ except fumarate and malate $\left(\mathrm{IO}^{-4} \mathrm{M}\right)$; vitamins at $2 \mathrm{mg} / 1$ and ammonium chloride at $7 \mathrm{~mm}$.

To prepare $\mathrm{I} 1$ of complete medium, ro $\mathrm{ml}$ of each of the nine stock solutions were added to $500 \mathrm{ml}$ of double-strength minimal medium, and the $\mathrm{pH}$ adjusted to 8.0 . For liquid medium, I $\mathrm{g}$ of $\mathrm{NaHCO}_{3}$ was added and the volume made up to I l; for solid medium the agar (I5 g) was added to $410 \mathrm{ml}$ of water and autoclaved separately. The diagnostic media were prepared by adding the supplements as indicated in the Table and adjusting the volume appropriately. The $\mathrm{pH}$ values of media I, II and III were adjusted to $8 \cdot 0$ and of IV to $9 \cdot 6$, before autoclaving.
\end{abstract}

\begin{tabular}{|c|c|c|c|c|}
\hline \multirow{2}{*}{$\begin{array}{l}\text { Supplement } \\
\text { group }\end{array}$} & \multicolumn{4}{|c|}{ Diagnostic medium } \\
\hline & I & II & III & IV \\
\hline I & + & 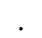 & . & . \\
\hline 2 & + & + & & . \\
\hline 3 & + & 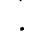 & + & \\
\hline 4 & + & & & + \\
\hline 5 & . & + & 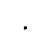 & . \\
\hline 6 & 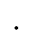 & + & + & \\
\hline 7 & . & + & . & + \\
\hline 8 & & 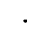 & + & \\
\hline 9 & . & . & + & + \\
\hline
\end{tabular}

Table 2. The effect of the $\mathrm{pH}$ of the complete medium on viability

$\begin{array}{ccc}\begin{array}{c}\text { Before } \\ \text { autoclaving }\end{array} & \begin{array}{c}\text { Of plate } \\ \text { (approx.) }\end{array} & \begin{array}{c}\text { Viability } \\ (\%)\end{array} \\ 6.5 & 6.5 & 47.8 \\ 7.0 & 7.0 & 41.6 \\ 7.5 & 7.0 & 86.5 \\ 8.0 & 7.0 & 100.0 \\ 8.5 & 7.0-7.5 & 95.3 \\ 9.0 & 7.5 & 85.1 \\ 9.5 & 7.5 & 79.6 \\ \text { I0.0 } & 7.5-8.0 & 71.5 \\ 10.5 & 8.0 & 21.5 \\ 11.0 & 8.5 & 3.5\end{array}$

a single nutritional requirement (or with multiple requirements contained in a single supplement group) will only grow on one or two of these media, and therefore the supplement group which satisfies the nutritional requirements of any mutant may be identified from the unique pattern of growth of each mutant on the diagnostic media. Mutants were partially identified in this way by reference to Table I. For example, a mutant requiring methionine (contained in group 2) grows on media I and II, and a mutant growing on media II and IV requires one or more vitamins (group 7). Mutants were further characterized by 
their growth on media containing separately the individual supplements of the group identified from the diagnostic media.

The individual supplements were arranged so that wherever possible those which are closely related biochemically were placed in the same group. This arrangement permits the detection of likely double (e.g. valine plus isoleucine) or alternative (e.g. serine or glycine) requirements. Certain mutants with alternative requirements in separate groups may grow on more than two diagnostic media; for example, those defective in sulphate reduction may have alternative requirements for cysteine (group 4) and methionine (group 2) and will therefore grow on diagnostic media I, II and IV.

Mutants isolated. Preliminary mutagenesis experiments using these media have led to the isolation and identification of mutants requiring biotin and methionine, and mutants defective in sulphate, nitrate and nitrite reduction. Five auxotrophic strains with novel phenotypes have also been isolated. These require respectively (i) thiamine, (ii) $p$-aminobenzoic acid, (iii) a combination of pyruvate or acetate plus malate or succinate or fumarate, (iv) serine or glycine, and (v) adenine.

S.F.D. acknowledges a University of Liverpool Research Studentship; this work was supported in part by the Science Research Council.

\section{REFERENCES}

AllEN, M. M. (1968). Simple conditions for the growth of unicellular blue-green algae on plates. Journal of Phycology 4, I-4.

Allen, M. M. \& Sмiтh, A. (1969). Nitrogen chlorosis in blue-green algae. Archiv für Mikrobiologie 69, $114-120$.

Asato, Y. \& Folsome, C. E. (I969). Mutagenesis of Anacystis nidulans by $N$-methyl- $N$ '-nitro- $N$-nitrosoguanidine and UV irradiation. Mutation Research 8, 53I-536.

Herdman, M. \& CarR, N. G. (I972). The isolation and characterization of mutant strains of the blue-green alga Anacystis nidulans. Journal of General Microbiology 70, 21 3-220.

Herdman, M., Faulkner, B. M. \& Carr, N. G. (1970). Synchronous growth and genome replication in the blue-green alga Anacystis nidulans. Archiv fïr Mikrobiologie 73, 238-249.

Holliday, R. (1956). A new method for the identification of biochemical mutants of microorganisms. Nature, London $\mathbf{1 7 8}, 987$.

Houghton, J. A. (197I). Attempted isolation of auxotrophic mutants from blue green algae. British Phycological Journal 6, 39-40.

Ingram, L. O., Pierson, D., Kane, J. F., Van BaAlen, C. \& Jensen, R. A. (1972). Documentation of auxotrophic mutation in blue-green bacteria: characterization of a tryptophan auxotroph in Agmenellum quadruplicatum. Journal of Bacteriology I1 1 , I $12-118$.

KANEY, A. R. \& Dolack, M. P. (1972). Temperature-sensitive mutants of Anacystis nidulans. Genetics 7r, $465-467$.

SRIVASTAVA, B. S. (1969). Ultraviolet induced mutations to growth factor requirement and penicillin resistance in a blue-green algae. Archiv für Mikrobiologie 66, 234-238.

Stevens, S. E. \& VAN BaAlen, C. (1970). Growth characteristics of selected mutants of a coccoid bluegreen alga. Archiv für Mikrobiologie 72, I-8.

TAKAHASHI, T. (1959). Filtration methods for selecting auxotrophic mutants of flocculent type yeast. Report of the Kihara Institute for Biological Research 1o, 57-62.

Van BaAlen, C. (1965). Mutation of the blue-green alga Anacystis nidulans. Science, New York 149, 70.

VAN BaAlen, C. (1973). Mutagenesis and genetic recombination. In The Biology of Blue-Green Algae, pp. 186-200. Edited by N. G. Carr \& B. A. Whitton. Oxford: Blackwell Scientific Publications. 